\title{
CONSTITUCIONALISMO FRATERNAL E DIREITOS HUMANOS: A IMPORTÂNCIA DO LAÇO SOCIAL DA FRATERNIDADE NO EXERCÍCIO DA DEMOCRACIA REPRESENTATIVA
}

Thiago Passos Tavares*

\section{RESUMO}

Carlos Augusto Alcântara Machado*

O objetivo da pesquisa é demonstrar a importância da fraternidade na democracia brasileira, caracterizada como representativa, ao menos em tese, visto que a vontade do povo não tem sido considera nas decisões que promovem mudanças legislativas substanciais. Diante disto surge a indagação central do presente estudo: Qual a contribuição da categoria da fraternidade em uma democracia? A metodologia aplicada a pesquisa é qualitativa e bibliográfica ao buscar fontes na doutrina jurídica relacionada com o tema e também quantitativa ao trazer dados como forma de argumentação. Justifica-se o estudo pela relevância da fraternidade na construção da democracia no Brasil.

Palavras-chave: Política. Democracia. Fraternidade. Participação popular. Direitos humanos.

\section{FRATERNAL CONSTITUTIONALISM AND HUMAN RIGHTS: THE IMPORTANCE OF THE FRATERNITY SOCIAL TIE IN THE EXERCISE OF REPRESENTATIVE DEMOCRACY}

\begin{abstract}
The objective of the research is to demonstrate the importance of fraternity in Brazilian democracy, characterized as representative, in theory, since the will of the people has not been considered in the decisions that promote substantial legislative changes. The central question of the present study arises: What is the contribution of the category of fraternity in a democracy? The methodology applied is qualitative and bibliographical when seeking sources in legal doctrine related to the subject and quantitative when bringing data as a form of argumentation. Justified the study by relevance of the fraternity in the construction of democracy in Brazil.
\end{abstract}

Keywords: Politics. Democracy. Fraternity. Popular participation. Human Rights.

\section{INTRODUÇÃO}

Vivencia-se no Brasil turbulentas transições políticas, jurídicas, sociais e humanas, digase aqui, desde mudanças na forma de exercer a autoridade e o poder, até mesmo a alterações legislativas das mais diversas. Dentre elas, a polêmica reforma política das leis trabalhistas e a nova proposta governamental de reformulação do sistema jurídico das normas previdenciárias brasileiras. Mudanças estas, em que o povo brasileiro tem enfrentado coercitivamente, ao contrariar o compromisso firmado no artigo $1^{\circ}$ caput da Carta Constitucional de 1988, que reza que "todo poder

\footnotetext{
* Advogado inscrito na Ordem dos Advogados do Brasil, Seccional Sergipe. Mediador judicial na Justiça Federal de Sergipe. Especialista em Direito Público pela Universidade Estácio de Sá - UNIESA. Mestrando em Direitos Humanos pela Universidade Tiradentes. E-mail: advogadothiagotavares@ gmail.com

* Procurador de Justiça do Ministério Público do Estado de Sergipe. Professor do Mestrado em Direitos Humanos da Universidade Tiradentes e do Mestrado em Direito da Universidade Federal de Sergipe. Doutor em Direito pela Pontifícia Universidade Católica de São Paulo. E-mail: cmachado@infonet.com.br.
} 
emana do povo", visto que, muito embora, o regime representativo não seja de caráter absoluto, revela-se repressivo e de empobrecimento político democrático, como demonstrar-se-á doravante.

O presente estudo visa demonstrar a importância da fraternidade para a democracia brasileira e, como a ausência desta, acarreta decisões políticas antidemocráticas em um cenário nomeado como participativo, na qual as comunidades desfavorecidas permanecem alijadas do processo, excluídas que são dos sistemas decisórios e discriminadas em todos os aspectos, sejam sociais, jurídicos, raciais ou políticos.

Para tanto, será apresentado um breve estudo das reformas políticas implementadas e pretendidas pelo Estado brasileiro na contemporaneidade, a exemplo da reforma trabalhista já concretizada e da proposta da reforma previdenciária.

No tocante as diretrizes utilizadas para a pesquisa, pretende-se o uso de um enfoque questionador $^{1}$, a partir da contestação da teoria nomeada como hegemônica, de concepção puramente eurocêntrica, com enfoque universalista, individualista, capitalista, liberal e ocidental $^{2}$, ao partir de uma análise centrada em teoria crítica $^{3}$, da filosofia da suspeita, através e consoante uma estrutura de pensamento reflexiva e reivindicativa dos direitos humanos.

Quiçá, tem-se como pressuposto fundamental que, as questões relativas às reformas ditas jurídicas atestam o caráter eminentemente político e, antes de tudo, são uma grave ofensa e desrespeito aos direitos humanos, visto que, especificamente, violam a dignidade do ser humano enquanto pessoa e, restringe a liberdade individual dos sujeitos da sociedade brasileira

\footnotetext{
${ }^{1}$ Ao tratar de direitos humanos em uma perspectiva crítica, Herrera Flores (2005, p.41) faz menção a importância em se observar o contexto de cada povo: "Cuando intentamos construir una teoría crítica de los derechos humanos y se nos hurtan los contextos en los que éstos se dan, chocamos con una y otra con la dura realidad de un mundo que nada tiene que ver con lo que tales filósofos de la política hegemónica afirman."

${ }^{2}$ Como profere o pensamento de Rubio (2016, p.65): "Por esta y otras razones, se puede afirmar que el concepto estrecho liberal y occidental de derechos humanos, tal como se interpreta y aplica, deja intactas las sociabilidades, las tramas sociales y relacionales propias del modo de vida capitalista que se basa en una división heterárquica, desigual y asimétrica estructural tanto del saber, del poder, del ser y del hacer (trabajo humano incluido), que discrimina, margina, domina y oprime desde el punto de vista de género, racial, de clase, etario y cultural. Por ello deja fuera de la posibilidad de disfrutar derechos a la mayor parte de la humanidad. Los derechos humanos visto solo desde sus dimensiones instituidas, burocráticas, formales, abstractas y normativas, invisibilidad, ignoran o no afectan a las situaciones estructurales de desigualdad y dominación que quedan inamovibles históricamente, a pesar de que existan normas e instituciones junto a reflexiones teóricas sobre ellas que puedan, formalmente, reconocer las demandas de esos grupos excluidos."

${ }^{3}$ Sobre a perspectiva ocidental e tradicional dos direitos humanos, Rubio (2012, p.10) faz considerações valiosas: "Teniendo en cuenta las posiciones conservadoras, y dada la fuerte influencia que tienen en la cultura jurídica occidental, desde mi punto de vista, al hablar de derechos humanos se utiliza un concepto demasiado simplista, estrecho y reducido. Considero que la idea de derechos humanos oficialmente aceptada y más generalizada en la cultura, tanto de las personas de la calle como del ámbito de los operadores jurídicos y de los teóricos de la academia, provoca cierta indolencia, docilidad y pasividad, además de que consolida la separación tradicionalmente reconocida entre la teoría y la práctica. Tengo la impresión de que los derechos humanos son como una especie de traje o vestido que se tiene que poner todo el mundo, incluso aquellos hombres y aquellas mujeres que no necesitan usarlo, porque tienen otra forma de concebir la ropa o porque sus figuras no encajan en ese molde (son más altas o más bajas, más anchas o más delgadas, más masculinas, más femeninas o ninguna de las dos)."
} 
e segue em sentido contrário ao modelo de democracia participativa que tem como fundamento a fraternidade substanciada no preâmbulo constitucional de 1988.

Nesse sentido, todo o debate é pautado com base na teoria crítica dos direitos humanos, na certeza de que, discutir as questões relativas a democracia e participação popular, implica afirmar um posicionamento em defesa da fraternidade, do reconhecimento das diferenças e de garantia de uma vida digna as pessoas humanas. Incluem-se nesse contexto, os empresários, os políticos, mas também os operários, os sindicalistas, os pobres, os miseráveis, os ruralistas, os índios, os afro-brasileiros, os estrangeiros, os quilombolas, os sem-terra e todos os outros sujeitos de direitos que são excluídos e discriminados na sociedade individualista.

Diante disto surge o problema central do artigo: Qual a contribuição da categoria da fraternidade em uma democracia representativa? A fraternidade pode contribuir para o reconhecimento das diferenças e inclusão dos indivíduos na sociedade?

A metodologia aplicada a pesquisa é qualitativa e bibliográfica ao buscar fontes na doutrina jurídica relacionada com o tema e também quantitativa ao trazer dados como forma de argumentação.

Justifica-se o estudo pela demonstração da importância da fraternidade em uma democracia representativa e participativa.

Para tanto, é essencial o entendimento sobre a importância da fraternidade em uma democracia representativa e como a ausência desta resulta em mercantilização dos seres humanos e privações das liberdades substantivas dos indivíduos, visto que são temas relevantes e balizadores da discussão.

Enfatiza-se, portanto, uma abordagem pautada sistematicamente na teoria crítica dos direitos humanos, não tradicionalista ou ocidental, que norteia a pesquisa como referencial teórico questionador, primariamente e principalmente através da pesquisa e estudos de obras de Daniela Ropelato, David Sánchez Rubio, Filippo Pizzolato, e Joaquín Herrera Flores, Leonardo Morlino e de modo subsidiários nas demais doutrinas pesquisadas e citadas no decorrer deste texto.

Especificamente, os objetivos da pesquisa estão centralizados no mapeamento de estudos com o intuito de: identificar os principais problemas da democracia representativa no Brasil; discutir a questão da ausência de representatividade nos processos de participação da sociedade; demonstrar a importância da categoria da fraternidade para o exercício da democracia brasileira. 


\section{DEMOCRACIA EMBLEMÁTICA E CONFORMISMO POLÍTICO}

A festa do voto nas eleições simboliza um dos únicos momentos que realmente está presente a verdadeira e direta democracia. Nos demais momentos do exercício do mandato, os atores políticos (RODRIGUES, 2013, p.21), prática e literalmente, assumem o poder e ignoram o desejo e a vontade do povo, através da democracia representativa e emblemática, na qual repercutem interesses de escala econômica e capitalista que visam apenas dominar o poder e obter lucratividade.

Monteiro, Moura e Lacerda, (2015, p.161) explicam sobre o papel fundamental da democracia:

A perspectiva formalista, minimalista e procedimental de democracia de
Schumpeter influenciou e têm relevância na literatura especializada. A
característica eleitoral e representativa ainda é uma das características
fundamentais daqueles que objetivaram classificar sistemas ou regimes
democráticos.

Assim, sobressaem processos notáveis de desvio de finalidades de instituições, inclusive pelas vias da corrupção, de fraudes, nepotismo, favorecimento, tráfico de influência, exploração, ou até mesmo por incentivo e promoção de discriminação, exclusão e preconceitos diversos.

Nessa perspectiva, cabe destacar o entendimento de Rubio (2016, p.45) ao discutir sobre o real papel da democracia: "Todo ser humano tiene que participar directamente en todo aquello que le afecta en el ámbito de lo público, sin que sea incompatible con el apoyo complementario de mecanismos de representación."

Não obstante, o papel democrático direto só é exercido no momento de digitar o número do candidato na urna eletrônica e apertar o botão verde "confirma". Após a diplomação, para a política (partidos políticos de todos os gostos com a mesma função) e para os políticos (agentes exploradores disseminados por todos os ângulos), o que importa na verdade é o poder, conquistado através do voto a cada quatro anos.

Nesse ponto, Monteiro, Moura e Lacerda (2015, p.174) explicam de modo simples e sucinto, mas com propriedade, que a democracia representativa somente se torna consubstanciada efetivamente, ou só se torna legítima, se combinada de alguma forma à democracia participativa. 
Democracia representativa que desaparece após o voto, visto que, quando eleitos, os políticos fazem o que planejavam para si próprios, não o que o povo almeja e de fato necessita e afeta. Coloca-se de lado políticas públicas e todos os interesses públicos e demandas reais das comunidades, permanecendo camuflados os interesses econômicos e particulares de uma minoria exploradora.

Ora, nessa direção aponta Tocqueville (2000, p.23) a importância da supremacia do interesse público em face do interesse dos governantes: "Para o bem das nações, é importante que os governantes sejam honestos e tenham talento; mas ainda mais importante é que os interesses dos governantes não conflitem com os da massa dos governados."

E quando porventura, os interesses sociais são satisfeitos pela efetivação de algum tipo de participação da população nos processos decisórios, diga-se de passagem, são raros os casos, acabam por tornarem-se expectativas frustradas, por vezes em virtude do desperdício inenarrável de recursos ou até mesmo pela ausência deste.

Diante desse ponto de visão, cabe destacar a perspectiva de Chauí (1990) acerca de cidadania ativa e participação política: "O espaço da cidadania ativa, portanto, é o da criação dos direitos, da garantia desses direitos e da intervenção, da participação direta no espaço da decisão política."

A partir deste prisma, percebe-se que, salvo em casos atípicos, contados a dedo, praticamente não existe participação ativa dos cidadãos na democracia brasileira ${ }^{4}$, visto que a maioria as mudanças realizadas em torno do ordenamento jurídico nacional, a exemplo de alterações em leis complementares e ordinárias, contaram com a vontade da maioria elitista que, unilateralmente, contamina a política em todos os seus aspectos, de modo sistêmico.

As reformas jurídicas contemporâneas podem ser consideradas políticas porque partem em sua maioria, não da vontade do povo ou da relação comunitária. Como nota Weber (2009, p.25): “a democracia deve representar participação e pertencimento: Relação social

\footnotetext{
${ }^{4}$ Sobre a notória separação paritária do poder e da ausência de democracia direta abordam Rubio (2016, p.50): "Con respecto a la democracia, el principio de separación se expresa a través de los pares democracia representativa/democracia participativa a democracia indirecta/democracia directa; poder estatal/poder ciudadano; poder constituyente/poder constituido; formas, procedimientos e instituciones/contenidos, sujetos y acciones ciudadanas. Por lo general, la democracia representativa o indirecta suele presentarse la democracia máximo exponente de la democracia, infravalorándose la democracia directa o participativa como su oponente natural o como un apéndice específico menor que no puede dar más de sí, sin que quepa opción alguna a posibles combinaciones complementarias, dialógicas e equitativas. Uno de los argumentos principales que se arguyen es que la democracia directa exponente es funcionalmente más operativa, siendo la democracia directa exponente de caos, desorden e inoperatividad."
} 
chama-se "relação comunitária" quando e na medida em que a atitude na ação social - no caso particular ou em média ou no tipo puro - repousa no sentimento subjetivo dos participantes."

Todavia, tem prevalecido os interesses dos partidos políticos ${ }^{5}$ e de seus membros, que correspondem de maneira efetiva aos modelos de democracia não participativa e sim apenas representativa. Decisões unilaterais entre partidos políticos aliados com interesses em comum, que se utilizam do poder para decidir o que os favorece ou negar o que os afeta.

$\mathrm{Na}$ dimensão da democracia representativa, destaca-se o entendimento de Freitas (2018, p.115):

A democracia representativa apresenta restrições para garantir, por si só, os direitos dos cidadãos. Isso requer a criação de espaços e canais de participação e confronto de projetos, nos quais os sujeitos coletivos possam expressar seus interesses e demandas orientando a administração pública no atendimento de suas necessidades básicas.

Na visão de Gianturco (2018, p. 261) define-se um partido político ${ }^{6}$ como: "um grupo no qual, as pessoas entram, alguns viram chefes, outros permanecem na base, com o objetivo de alcançar vantagens, pessoais e coletivas.”

Especificamente se enfatiza o tema "partidos políticos" a fim de demonstrar como o povo é excluído dos processos de participação, enquanto políticos utilizam-se dos partidos para obter vantagens diversas ao sentido democrático.

É perfeitamente possível citar uma infinidade de ocasiões, em que o povo sequer manifestou interesse em modificações normativas através de sindicatos, passeatas ou qualquer outro tipo de discurso ou pronunciamento popular no sentido de reformar as normas previdenciárias ou as leis trabalhistas. No entanto, os próprios deputados e senadores votaram acerca do tema proposto por eles mesmos e decidiram aprovar ou reprovar sem mesmo ouvir a população, a parte mais afetada.

\footnotetext{
${ }^{5}$ A respeito da conceituação de partidos políticos ressaltam-se as palavras de Novelino (2018, p.262): “Os partidos políticos são pessoas jurídicas de direito privado, cuja existência começa com a inscrição do ato constitutivo no respectivo registro (CC, arts. 44, V, e 45; Lei 9.096/1995, art. $7^{\circ}$ ), momento em que adquirem personalidade jurídica. Após adquirida a personalidade jurídica, na forma da lei civil, os partidos devem registrar seus estatutos no Tribunal Superior Eleitoral $\left(\mathrm{CF}\right.$, art. $17, \S 2^{\circ}$ ), sendo-lhes assegurados o direito aos recursos do fundo partidário e o acesso gratuito ao rádio e à televisão, na forma da lei."

${ }^{6}$ A concepção de Gianturco (2018, p.262) demonstra aspectos históricos da formação de partidos políticos: "Historicamente, os partidos políticos são um fenômeno muito recente e são apenas uma das várias formas que tomaram os grupos de interesse e de pressão. Posições, ideias, ideologias e interesses já se articularam em clãs, famílias, etnias, classes sociais, raças, categorias profissionais. O termo técnico mais preciso para definir todos esses diferentes tipos de agrupamentos políticos é "facções"."
} 
Como exemplo de ausência de participação da população nos processos decisórios e legislativos governamentais, destaca-se a Lei da Reforma Trabalhista (Lei 13.467/2017) que promoveu mudanças significativas nas normas trabalhistas.

\section{A REFORMA TRABALHISTA COMO EXEMPLO DA INEXISTÊNCIA DE PARTICIPAÇÃO POPULAR NOS PROCESSOS DEMOCRÁTICOS}

A Lei 13.467/2017, conhecida como Lei da Reforma Trabalhista, altera diversas disposições legais previstas na Consolidação das Leis Trabalhistas. Dentre as principais mudanças, destacam-se a possibilidade de condenação do trabalhador ao pagamento de custas e honorários advocatícios, grave ofensa ao princípio de acesso à justiça e a extinção da obrigatoriedade de contribuição sindical.

A mitigação do acesso a justiça é um reflexo histórico da ausência de fraternidade nos sistemas de participação da sociedade brasileira. Demonstra como o Estado tem adotado um modelo individualista e explorador. Sobre esse ponto crucial Jaborandy (2018, p.68) leciona o seguinte: “A ausência de fraternidade remonta a origem do Brasil e sua formação colonial. Os reflexos políticos e jurídicos de tal formação, que se prolongam no tempo, com outras formas de exploração, subserviência e ostracismo político participativo [...]”.

Em primeiro lugar, se observa que, enquanto o empresário torna-se cada vez mais rico e poderoso, a classe trabalhadora é explorada e humilhada, conforme define Marx (1996, p.332) em sua obra $O$ capital, ao tratar de mais-valia e da exploração do trabalhador: "A taxa de maisvalia é, por isso, a expressão exata da taxa de exploração da força de trabalho pelo capital ou do trabalhador pelo capitalista".

Todavia, vale frisar que, conforme aponta Oliveira (2010, p.46), não é através da abolição dos $\operatorname{conflitos}^{7}$, proposta por Marx, por meio de um modelo socialista que se constrói uma democracia sólida e sim através das lutas, pelo reconhecimento das diferenças gerados por uma perspectiva conflituosa.

\footnotetext{
${ }^{7}$ Conforme leciona Mouffe (2014, p. 758) a respeito da perspectiva do conflito: "El discurso de igualdad y ciudadanía en la escuela es el lema de la homogeneización. Al afirmar el antagonismo como elemento constitutivo de la democracia y rechazar la idea de un consenso que sea capaz de conciliar toda diferencia en torno de principios universales, estamos operando con la dimensión de "Lo Político", a partir de la cual buscamos comprender los mecanismos institucionales de expresión y silenciamiento de la diferencia étnicas, religiosas, de orientación sexual, generacionales, de género, de constitución familiar etc.)."
} 
Em relação aos direitos humanos em uma linha de argumentação crítica acerca da igualdade e da diferença, destacam-se as palavras de Santos (2003, p.56): "temos o direito a ser iguais quando a diferença nos inferioriza e temos o direito a ser diferentes quando igualdade nos trivializa."

Sobre o sentido da igualdade, revelam-se em direção contrária as novas normas trabalhistas nacionais, em que se chega ao ponto de a justiça condenar trabalhadores ao pagamento de custas processuais, perícias técnicas e honorários sucumbenciais, conforme pronunciado nos artigos 789, 790 e 791-A, respectivamente, todos previstos na Lei 13.467/2017, conhecida também, como Lei da Reforma Trabalhista.

À guisa de esclarecimento sobre a Lei da Reforma Trabalhista, aborda Schiavi (2017, p. 9):

"A Lei n. 13.467/17, conhecida como a Lei da Reforma Trabalhista, aprovada pelo Congresso Nacional e sancionada pelo Presidente da República, traz importantes alterações no Direito do Trabalho, no Processo do Trabalho e na Justiça do Trabalho. A lei é polêmica, pois em diversos dispositivos, muitos apontam precarização das condições de trabalho e restrição ao acesso do trabalhador ao Judiciário."

Em consonância com as novas normas trabalhistas, Frazão (2017) menciona os aspectos da reforma: “A reforma trabalhista prevê que o empregado que entrar com uma ação na Justiça contra a empresa e perder poderá ter que arcar com as custas do processo. De acordo com o texto, os chamados honorários de sucumbência serão de 5\% a $15 \%$ do valor da ação."

Nessa direção, além de tudo, dependendo da situação, o trabalhador ainda poderá ser condenado em determinados casos por litigância de má-fé, como denota o dispositivo contido na redação do artigo 793-A da nova norma trabalhista, destacado, com sabedoria, por Schiavi (2017, p. 86): "Na linguagem popular, diz-se que o processo não é instrumento para se levar vantagem, por isso, todos os sujeitos que nele atuam principalmente os atores principais (juiz, advogados, autores e réus), devem pautar-se acima de tudo pela ética e honestidade."

A esse respeito, é relevante ter conhecimento dos dados levantados pela Coordenadoria de Estatística e Pesquisa do Tribunal Superior do Trabalho no mês de setembro de 2018, que demonstram no gráfico 1 o reflexo de um ano da vigência da Lei da Reforma Trabalhista: 


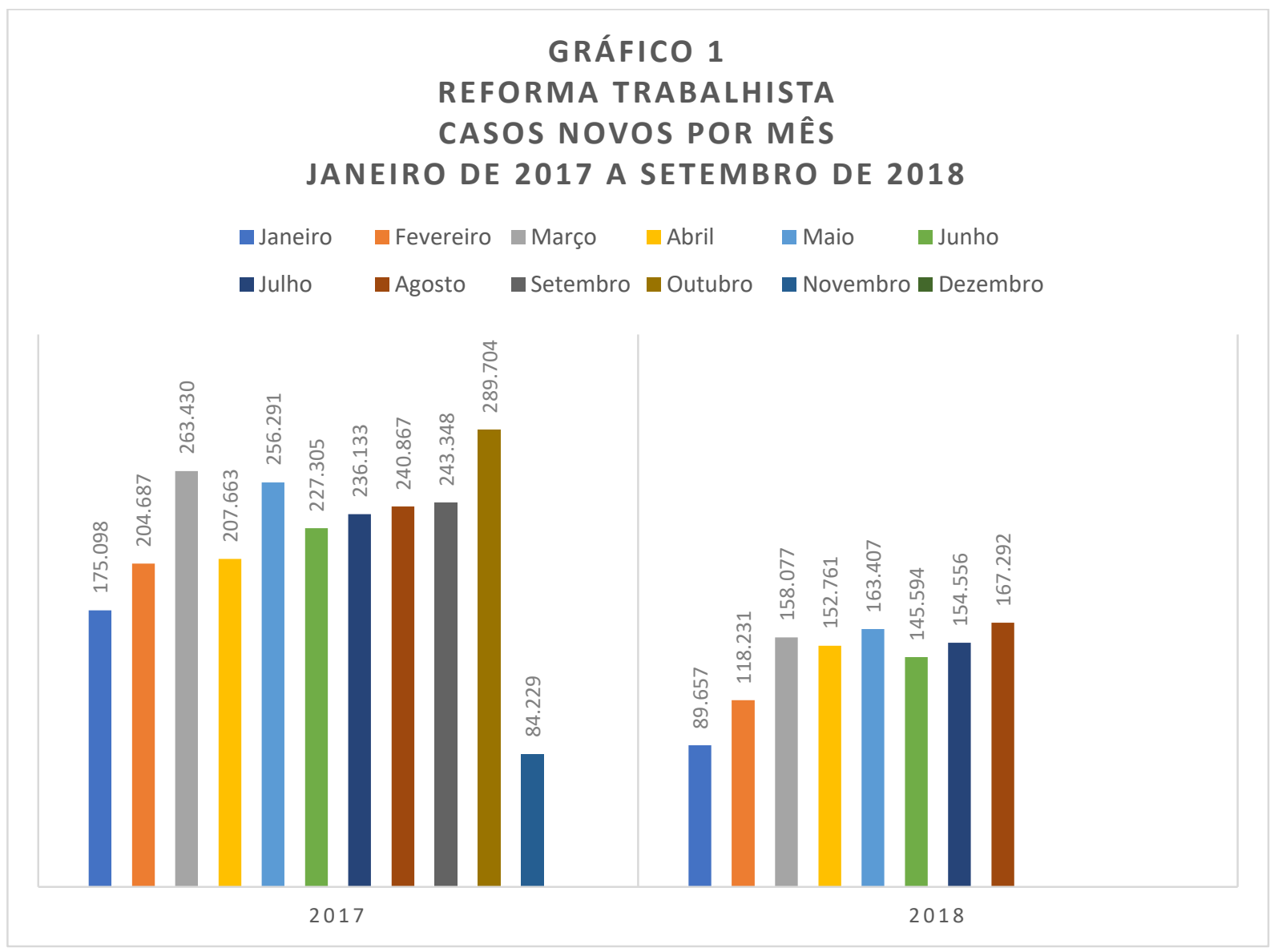

Fonte: Gráfico elaborado pelos Autores com base nos dados da Coordenadoria de Estatística do Tribunal Superior do Trabalho (TST, 2018).

O resultado prático da Lei de Reforma Trabalhista ${ }^{8}$ é límpido no sentido da diminuição dos ajuizamentos de processos trabalhistas (desafoga o Judiciário e reduz significativamente o número de proposituras trabalhistas a serem julgadas pelos magistrados, ao diminuir o fluxo de trabalho dos juízes e assistentes judiciários), pois aqueles trabalhadores que antes lutavam por direitos humanos ${ }^{9}$ e sociais, experimentam o receio da condenação por litigância de má-fé, ao pagamento de custas processuais, indenizações e honorários sucumbenciais aos seus empregadores, enquanto isso, empresários se beneficiam em todos os sentidos.

\footnotetext{
${ }^{8}$ Em respeito a redução da propositura de demandas trabalhistas, Pannunzio (2018) explica a significativa redução de ajuizamentos no início do ano de 2018: "Quase cinco meses depois de entrar em vigor, as mudanças nas leis trabalhistas já reduziram o número de ações na Justiça. Só em São Paulo, a quantidade de processos caiu quase pela metade no primeiro trimestre de 2018."

${ }_{9}^{9}$ Sobre os direitos humanos, ensina Herrera Flores (2005, p.49): "Quedándonos, por el momento, en el plano tradicional de la lucha jurídica, si desde la teoría no somos capaces de reapropiarnos del derecho como instrumento de positivación de las prácticas sociales, terminamos confundiendo a todos aquellos que con su mejor voluntad luchan jurídicamente por la consecución de la dignidad humana en todas las partes del mundo. No se trata, pues, de negar as tradicionales y más difundidas formas de tratar teórica y prácticamente los derechos humanos, sino de reapropiárnoslas crítica y contextualizada, ampliando sus deficiencias y articulándolas con tipos diferentes de prácticas de mayor contenido político, económico y social."
} 
Notadamente, as novas normas trabalhistas operam-se em desfavor ao princípio do acesso à justiça, visto que as comunidades (diga-se os trabalhadores), sem vozes, além de não participarem ativamente das decisões no que tange direitos sociais, são obrigadas a silenciar diante dos abusos de direitos humanos praticados por empregadores, detentores do capital.

Sobre a redução dos direitos dos trabalhadores, refere Tomaz (2012, p. 95), relativamente aos direitos sociais: "Têm-se reduzido os direitos sociais, especialmente os dos trabalhadores, aniquilando-se com a proteção à despedida arbitrária, reduzindo-se salários, amesquinhando-se aposentadorias, tudo em nome de uma reforma social”.

A indigitada reforma social tem mais um caráter político do que comunitário ou de interesse público e, no que tange o fundamento do Estado Democrático de Direito, como a dignidade da pessoa humana e as condições básicas de sobrevivência ou o mínimo existencial, são massivamente prejudicados em todas as direções inimagináveis do campo político, jurídico, social e econômico.

É sabido que os atores que possuem capital econômico e financeiro, os "donos do poder", são capazes de influenciar nos processos decisórios, como bem explica Weber (2009), no sentido da probabilidade de se levar adiante a sua vontade em contraposição a vontade de outras pessoas.

Não obstante, o quadro que se extrai é que, muito embora o significado de democracia englobe a participação da sociedade, em virtude da seletividade dos processos de participação e da "escravidão" representativa, na qual, apenas os representados por detentores de capitais econômicos opinam nas mudanças políticas e legislativas no Brasil, os demais atores sociais, a exemplo dos pobres, dos índios, afro-brasileiros e demais classes discriminadas, são impedidos de participar de forma ativa através da exclusão social, política, e jurídica.

Por conseguinte, em sentido contrário ao princípio da fraternidade e da democracia, a reforma flexibilizou as normas trabalhistas, ao extinguir a obrigatoriedade de contribuição sindical, com a nova redação do artigo 582 da Consolidação das Leis Trabalhistas, como um reflexo plenamente contrário ao regime democrático.

Ademais, mostra-se necessária a relação entre a fraternidade e a participação da sociedade nos movimentos sociais, nas organizações sem fins lucrativos, nos sindicatos e demais entidades no sentido de fortalecer os laços comunitários em busca de justiça social. 


\section{A IMPORTÂNCIA DOS LAÇOS DE FRATERNIDADE NOS PROCESSOS DE PARTICIPAÇÃO POPULAR}

A participação popular é o elemento central em uma democracia representativa ${ }^{10}$. É necessário ter responsabilidade social e multiplicar as oportunidades de participação com a adoção de posturas inclusivas dos sujeitos das comunidades locais, principalmente as mais discriminadas.

Desta forma, seguindo essa linha de pensamento, a respeito da previsão constitucional brasileira no tocante a participação popular e da responsabilidade social, destacam-se as palavras enunciadas por Machado (2016, p.70) sobre constitucionalismo fraternal ${ }^{11}$ : "a participação popular, decorrente da responsabilidade coletiva e social de todos os cidadãos, em vista da busca pessoal e comunitária do bem comum, apresentou-se, como instrumento de fraternidade".

Oportuno trazer à baila, a definição dos princípios democráticos elencados por Morlino (2005, p.46) para promoção dos direitos humanos, dos direitos sociais e da efetivação da democracia representativa, quais sejam: inclusão; participação; igualdade de voto; e responsabilidade.

Notadamente, a inclusão é um ponto importante a ser discutido no que tange a democracia representativa, primeiro pelas desigualdades sociais apresentadas no contexto nacional. Em segundo lugar, pelo quadro nítido de exclusão e discriminação de muitas comunidades, a exemplo das indígenas e quilombolas ou outros seguimentos minoritários, tradicionalmente excluídos.

Nessa linha, Ropelato (2007, p.103-104) aponta que um olhar através da fraternidade oferece uma proposta de redefinição dos laços sociais no sentido de construção do reconhecimento das diferenças entre indivíduos e de pertencimento dos atores culturais a sociedade.

Ressalta-se que a fraternidade possui um caráter dinâmico e através dela é possível oferecer elementos inovadores à democracia, capazes de desobstruir práticas contrárias a

\footnotetext{
${ }^{10}$ Vale frisar o entendimento de Rocha $(2013$, p.256) sobre o consenso comunitário: "A facticidade do governo representativo como elemento de composição de uma sociedade democrática expressa a suposta existência do consenso comunitário."

${ }^{11}$ Sobre constitucionalismo fraternal, acrescenta Britto (2003, p.216): “fase em que as constituições incorporam às franquias liberais e sociais de cada povo soberano a dimensão da fraternidade."
} 
democratização participativa, através da promoção do pertencimento e participação dos membros mais fracos, excluídos e discriminados.

Britto (2007, p.34-35) reconhece a fundamental importância de uma democracia fraternal, principalmente pela positivação dos mecanismos de defesa, a exemplo da: “consagração de um pluralismo conciliado com o não preconceito [art. $1^{\circ}, \mathrm{V}$ e $\operatorname{art.~} 3^{\circ}, \mathrm{IV}$ ], especialmente servido por políticas públicas e de ações afirmativas que operem como forma de compensação das desvantagens históricas sofridas por certos grupamentos sociais".

Destaca-se Pizzolato (2007, p.124) ao discutir a importância do princípio da fraternidade jurídica e dos mecanismos de balanceamento dos direitos e deveres em uma sociedade democrática. Explica: “[...] mecanismos (legislativos e jurídicos) de balanceamento visam a evidenciar as direções de desenvolvimento de liberdades individuais que salvaguardem, aliás, que promovam as razões da comunidade e, dentro dela, as razões dos mais fracos."

A respeito de democracia fraternal Machado (2016, p.71) acrescenta que: "Fraternidade e Democracia são faces da mesma moeda e podem se encontrar na prática, cada vez mais efetiva, como direito, mas também como dever cidadão, da democracia participativa".

Não obstante, cabe destacar, a lição de Ropelato (2008, p.106) sobre o princípio da responsabilidade compartilhada e sua importância efetividade de uma democracia representativa: “A fraternidade aparece como um princípio de responsabilidade compartilhada sobre a produção de bens públicos, em que a função política de mediação reforça as relações de reciprocidade entre os diversos bens legítimos, próprios da sociedade civil."

Por outro lado, a democracia representativa deve respeitar ainda, os limites da solidariedade horizontal, no escólio de Machado (2017, p.206): “A fraternidade deverá ser compreendida nos limites da solidariedade horizontal, que consiste na responsabilidade de socorro mútuo entre os próprios cidadãos"

Nessa linha de argumentação, se enfatiza a importância da fraternidade para garantir a qualidade democrática de uma dada sociedade, como concluiu a jurista italiana Ropelato (2008, p.109):

A fraternidade é capaz de expressar realmente o coração inteligente da democracia, ou seja, ampliar sua capacidade de harmonizar o que é autenticamente humano dentro das formas normativas necessárias à organização da convivência dos homens e dos povos. 
Pelo aduzido, vale lembrar as palavras de Sen (2010, p.10) sobre o desenvolvimento: “consiste na eliminação de privações de liberdade que limitas as escolhas e oportunidade das pessoas de exercer ponderadamente sua condição de agente. A eliminação de privações de liberdades substanciais [...]"

Por fim, agrega-se que, através da fraternidade, há maximização tanto das capacidades, como das responsabilidades dos cidadãos, ao ampliar as liberdades e propiciar igualdade entre as pessoas.

\section{CONSIDERAÇÕES FINAIS}

A democracia representativa não se restringe a participação eleitoral dos cidadãos, assim como o voto não é o único instrumento de exercício de cidadania ativa. A participação social envolve a relação entre o público e o privado, de fraternidade e uso dos instrumentos de gestão democrática para construção das políticas públicas inclusivas.

A fraternidade é um elemento essencial e humanizador em uma democracia por promover um laço de responsabilidade compartilhada, o reconhecimento das diferenças e a redução das desigualdades sociais.

Democracia vai muito além do sufrágio universal. A sociedade precisa estar informada, acompanhar a atuação dos gestores, cobrar prestação de contas, participar das decisões, além de fiscalizar a execução das políticas e demandas sociais.

A qualidade da democracia depende do comprometimento fraternal dos indivíduos para com as demandas sociais e a efetividade na adoção de medidas que solucionem, de modo efetivo, os problemas das comunidades mais necessitadas.

Mostra-se necessário promover a fraternidade para que se possibilite igualdade de condições e oportunidades para que as pessoas possam desenvolver suas capacidades e consolidar as liberdades de escolha entre os menos favorecidos.

Nessa perspectiva, conclui-se que a configuração de um regime democrático, acima de tudo, deve proporcionar práticas políticas fraternais e humanizadoras de justiça, equidade, desenvolvimento e responsabilidade social.

Ademais, não existe democracia, sem participação da população; nem liberdade, sem igualdade de condições e não é possível se falar em reconhecimento das diferenças sem a presença do laço social da fraternidade. 


\section{REFERÊNCIAS}

BRASIL. Lei $\mathbf{n}^{\mathbf{0}}$ 13.467, de 13 de julho de 2017. Altera a Consolidação das Leis do Trabalho (CLT), aprovada pelo Decreto-Lei no 5.452, de 1o de maio de 1943, e as Leis nos 6.019, de 3 de janeiro de 1974, 8.036, de 11 de maio de 1990, e 8.212, de 24 de julho de 1991, a fim de adequar a legislação às novas relações de trabalho. Disponível em http://www.planalto.gov.br/ccivil_03/_ato2015-2018/2017/lei/L13467.htm (Acesso em: 17 nov. 2018.

BRITTO, Carlos Ayres. Teoria da Constituição. Rio de Janeiro: Forense, 2003.

BRITTO, Carlos Ayres. Humanismo como categoria constitucional. Belo Horizonte: Fórum, 2007.

CHAUÍ, Marilena. Sociedade, Estado, OAB. In: XIII Conferência Nacional da OAB, Conselho Federal da OAB. Belo Horizonte: Anais, 1990.

FLORES. Joaquín Herrera. Los derechos humanos como productos culturales: crítica del humanismo abstracto. Pamplona: Catarata, 2005.

FONSECA, Reynaldo Soares da. O princípio jurídico da fraternidade na jurisprudência do STF e STJ. In: MACHADO, Carlos Augusto Alcântara; JABORANDY, Clara Cardoso Machado; BARZOTTO, Luciane Cardoso. Direito e fraternidade: em busca de concretização. Aracaju: EDUNIT, 2018.

FRAZÃO, Heliana. Após reforma trabalhista, juiz condena trabalhador por má-fé. Estadão. Revista Época Digital. 13 de novembro de 2017. Disponível em: https://exame.abril.com.br/brasil/trabalhador-na-ba-e-condenado-a-pagar-r-85-mil-emhonorarios/ Acesso em: 20 out. 2018.

FREITAS, Leana Oliveira. Políticas públicas, descentralização e participação popular. Rev. Katálysis [online]. 2015, vol.18, n.1, pp. 113-122. ISSN 1982-0259.

GIANTURCO, Adriano. A ciência da política uma introdução. 2.ed. Rio de Janeiro: Forense, 2018 .

JABORANDY, Clara Cardoso Machado. A efetivação de direitos fundamentais transindividuais e o princípio jurídico da fraternidade. In: MACHADO, Carlos Augusto Alcântara; JABORANDY, Clara Cardoso Machado; BARZOTTO, Luciene Cardoso. Direito e fraternidade: em busca de concretização. Aracaju: EDUNIT, 2018.

MACHADO, Carlos Augusto Alcântara. Fraternidade e democracia: considerações sobre os mecanismos de participação popular e fraterna na Carta Constitucional do Brasil de 1988. In: VERONESE, Josiane Rose Petry. O direito no Século XXI - o que a Fraternidade tem a dizer 
- Estudos desenvolvidos no Programa de Pós-Graduação em Direito da UFSC. Florianópolis: Insular, 2016.

MACHADO, Carlos Augusto Alcântara. A fraternidade como categoria jurídica: fundamentos e alcance (expressão do constitucionalismo fraternal). Curitiba: Appris, 2017.

MAQUIAVEL, Nicolau. O Príncipe. Tradução de Lívio Xavier. São Paulo: Abril Cultural, Coleção Os Pensadores, 1973.

MARX, Karl. O capital: crítica da economia política. São Paulo: Nova Cultura, 1996.

MAZZA, Alexandre. Manual de Direito Administrativo. 3. ed. São Paulo: Saraiva, 2013.

MONTEIRO, Lorena Madruga; MOURA, Joana Tereza Vaz de; LACERDA, Alan Daniel Freire. Teorias da democracia e a práxis política e social brasileira: limites e possibilidades. Sociologias, Porto Alegre, v. 17, n. 38, p. 156-191, abr. 2015. Disponível em: http://www.scielo.br/scielo.php?script=sci_arttext\&pid=S1517$45222015000100156 \& \operatorname{lng}=$ pt\&nrm=iso. Acesso em: 01 set. 2018.

MORLINO, Leonardo. Democracias y democratizaciones. México: Centro de Estudios de Política Comparada, 2005.

MOUFFE, Chantal et al. Democracia y conflicto en contextos pluralistas: entrevista con Chantal Mouffe. Hist. Cienc. Saúde - Manguinhos, Rio de Janeiro, v. 21, n. 2, p. 749-762, jun. 2014. Disponível em: http://www.scielo.br/scielo.php?script=sci_arttext\&pid=S0104$59702014000200749 \& \operatorname{lng}=$ pt\&nrm=iso. Acesso em: 25 out. 2018.

NOVELINO, Marcelo. Manual de Direito Constitucional. 9. ed. Rio de Janeiro: Forense, 2014.

OLIVEIRA, Luciano. O enigma da democracia. O pensamento de Claude Lefort. Piracicaba: Jacinta Editores, 2010.

PANNUNZIO, Fabio. Reforma trabalhista reduz número de ações na justiça. Band Notícias. 10 de abril de 2018. Disponível em: https://tvuol.uol.com.br/video/reformatrabalhista-reduz-o-numero-de-acoes-na-justica-04024E983668C8A16326. Acesso em: 20 nov. 2018.

PIZZOLATO, Filippo. A fraternidade no ordenamento jurídico italiano. In: O princípio esquecido/1: a fraternidade na reflexão atual das ciências políticas. BAGGIO, Antônio Maria. Vargem Grande Paulista: Cidade Nova, 2008.

RODRIGUES, Marta Maria Assumpção. Políticas Públicas. São Paulo: Publifolha, 2013. ROCHA, Maria Elizabeth Guimarães Teixeira. Democracia, direito e legitimidade. Uma discussão sobre os novos rumos do contrato social. In: O Capitalismo Humanista e Direitos 
Humanos. SAYEG, Ricardo Hasson; BALERA, Wagner. Florianópolis: Conceito Editorial, 2013.

ROPELATO, Daniela. Notas sobre participação e fraternidade. In: BAGGIO, Antônio Maria. O princípio esquecido/1: a fraternidade na reflexão atual das ciências políticas. Vargem Grande Paulista: Cidade Nova, 2008.

RUBIO, David, Sánchez. Derechos humanos, no colonialidad y otras luchas por la dignidad: una mirada parcial y situada. In: OLIVEIRA, Liziane Paixão Silva; MARINHO, Maria Edelvacy; ALVES, Gleisse Ribeiro. Direitos humanos: perspectiva internacional e nacional. Aracaju: EDUNIT, 2016.

RUBIO, David Sánchez. Por una recuperación de las dimensiones instituyentes de democracia y de derechos humanos. In: RUBIO, David Sánchez; OLIVEIRA, Liziane Paixão Silva; DORNELLES, Carla Jeane Helfemsteller Coelho. Teorias críticas e direitos humanos. Curitiba: CRV, 2016.

RUBIO, David Sánchez. Sobre el concepto de historización: una crítica a la visión sobre las degeneraciones de derechos humanos. Revista PRAXIS, n. 67, p. 9-22, 2012.

SANTOS, Boaventura de Sousa. Reconhecer para libertar: os caminhos do cosmopolitismo multicultural. Rio de Janeiro: Civilização Brasileira, 2003.

SCHIAVI, Mauro. A reforma trabalhista e o processo do trabalho: aspectos processuais da Lei n. 13.467/17. São Paulo: LTr Editora, 2017.

SEN, Amartya. Desenvolvimento como liberdade. Tradução Laura Teixeira Motta; revisão técnica Ricardo Doninelli Mendes. São Paulo: Companhia das Letras, 2010.

TOMAZ, Carlos Alberto Simões de. Democracia e jurisdição: entre o texto e o contexto. São Paulo: Baraúna, 2011.

TOCQUEVILlE, Alexis de. A democracia na América: sentimentos e opiniões; tradução Eduardo Brandão. São Paulo: Martins Fontes, 2000.

TST, Tribunal Superior do Trabalho. Primeiro ano da reforma trabalhista: efeitos. Notícias do TST. Secretaria de Comunicação Social. Brasília. 05 nov. 2018. Disponível em: http://tst.jus.br/noticias/-/asset_publisher/89Dk/content/id/24724445 Acesso em: 26 nov. 2018. VERONESE, Josiane Rose Petry. O direito no Século XXI - o que a Fraternidade tem a dizer - Estudos desenvolvidos no Programa de Pós-Graduação em Direito da UFSC. Florianópolis: Insular, 2016.

WEBER, Max. Economia e sociedade. Brasília: UNB, 2009.

WEBER, Max. Sociologia. 6. ed. São Paulo: Ática, 2003. 